\title{
TCF7 knockdown inhibits the imatinib resistance of chronic myeloid leukemia K562/G01 cells by neutralizing the Wnt/ק-catenin/TCF7/ABC transporter signaling axis
}

\author{
HUI ZHANG ${ }^{1}$, YONGHONG WANG ${ }^{1}$, HAO YANG $^{1}$, ZHENGLAN HUANG $^{1}$, XIN WANG ${ }^{2}$ and WENLI FENG ${ }^{1}$ \\ ${ }^{1}$ Department of Clinical Hematology, School of Laboratory Medicine, Chongqing Medical University; \\ ${ }^{2}$ Department of Hematology, The First Affiliated Hospital, Chongqing Medical University, Chongqing 400016, P.R. China
}

Received June 6, 2020; Accepted November 13, 2020

DOI: $10.3892 /$ or.2020.7869

\begin{abstract}
Clinical resistance to ABL tyrosine kinase inhibitor (TKI) imatinib remains a critical issue in the treatment of chronic myeloid leukemia (CML). Transcription factor 7 (TCF7) is one of the main $\mathrm{Wnt} / \beta$-catenin signaling mediators. Previous studies have shown that TCF7 is vital for tumor initiation, and targeting TCF7 can reduce drug resistance in many types of cancer. However, the role of TCF7 in CML imatinib-resistant cells is unclear. In the present study, we analyzed the transcriptomic data from CML clinical samples in the Gene Expression Omnibus (GEO) and performed experimental verification in the CML imatinib-resistant cell line K562/G01. We found that the expression of TCF7 was independent of BCR-ABL1 activity. Silencing of TCF7 downregulated the expression levels of CTNNB1, CCND1, and $\mathrm{ABCC} 2$, and therefore inhibited proliferation, weakened colony formation, and increased the drug sensitivity of imatinib-resistant cells. After analyzing the transcriptomic data of four groups (Scramble, TCF7_KD, Scramble+imatinib, and TCF7_KD+imatinib) using bioinformatics, we noted that Wnt/ $\beta$-catenin and ATP-binding cassette (ABC) transporter signaling pathways were upregulated in imatinib-resistant cells under conventional dose of imatinib, and TCF7 knockdown could neutralize this effect. Next, using ChIP-qPCR, we demonstrated that TCF7 was recruited to the promoter region of $A B C C 2$ and activated gene transcription. In summary, our results highlight that the upregulation of $\mathrm{Wnt} / \beta$-catenin and $\mathrm{ABC}$ transporter signaling pathways induced by imatinib treatment of resistant cells confers imatinib resistance, and reveal that targeting TCF7 to regulate the Wnt/ $\beta$-catenin/TCF7/ABC
\end{abstract}

Correspondence to: Dr Wenli Feng, Department of Clinical Hematology, School of Laboratory Medicine, Chongqing Medical University, Chongqing 400016, P.R. China

E-mail: fengwl@cqmu.edu.cn

Key words: chronic myeloid leukemia, imatinib resistance, TCF7, ATP-binding cassette transporters, Wnt/ $/$-catenin signaling pathway transporter signaling axis may represent an effective strategy for overcoming imatinib resistance.

\section{Introduction}

The molecular basis of chronic myeloid leukemia (CML) is the BCR-ABL1 oncoprotein, which results from a chromosomal translocation $\mathrm{t}(9 ; 22)$ ( $\mathrm{q} 34 ; \mathrm{q} 11)$ in hematopoietic stem cells (1). The clinical course of CML includes the chronic phase, accelerated phase, and blast crisis in sequence. For patients with chronic phase CML, main molecular remission (MMR) can be obtained in $74 \%$ of patients through treatment with imatinib, a tyrosine kinase inhibitor (TKI) targeting the BCR-ABL1 oncoprotein (2). However, $26 \%$ of chronic phase CML patients experience disease progression and treatment failure due to resistance and intolerance of treatment (3). For patients with accelerated phase or blast crisis CML, their leukemia cells show significant resistance to imatinib; complete cytogenetic remission (CCR) can be achieved in only $230 \%$ of patients through treatment with second-generation TKI (4). In addition, patients who respond effectively to drugs at the beginning of treatment may also develop secondary resistance due to the evolution of leukemia cells under the pressure of drug treatment (5). The updated TKI can effectively solve the resistance caused by a BCR-ABL1 point mutation (6). However, primary and secondary BCR-ABL1-independent resistance has become an prominent clinical problem in the treatment of CML.

The mechanisms underpinning TKI resistance in CML occur at multiple levels. First, at the cellular level, the heterogeneity of leukemia stem cells (LSCs) and the evolution driven by drug selection pressure lead to the formation of drug-resistant dominant clones (7). Progeny cells from these clones have a strong ability to proliferate, and lose the ability to differentiate into relatively mature blood cells. Second, genome instability leads to new molecular abnormalities. For example, the formation of the NUP98-HOXA9 fusion gene leads to rapid disease progression (8). In addition, point mutations in the kinase domain of the $B C R-A B L 1$ fusion gene cause a reduction in the drug binding efficiency (9). Third, there are abnormalities in the regulation of molecular signaling pathways, such as those involved in hematopoietic stem cell development 
(Wnt/ $\beta$-catenin, Hif-1 $\alpha$ ) (10-12), autophagy (ATG4B) (13) and epigenetic regulation (PRMT5, SIRT1) $(14,15)$. Moreover, the abnormal overexpression of BCR-ABL1 (16) and drug efflux mediated by ATP-binding cassette (ABC) transporters (ABCB1 or ABCC2) $(17,18)$ also play an essential role in TKI resistance.

Transcription factor 7 (TCF7) is one of the members of the TCF/LEF family (TCF7, TCF7L1, TCF7L2, LEF1), which functions downstream of the $\mathrm{Wnt} / \beta$-catenin signaling pathway. The protein encoded by this gene contains a $\beta$-catenin binding domain (CBD) and a high mobility group (HMG) domain. TCF7 can recognize and bind to the DNA sequence called Wnt response element (WRE) through the HMG domain, cause conformational changes of DNA and chromatin that lead to further binding of other transcription complexes (19), and promote the expression of Wnt target genes (20). Previous studies have shown that TCF7 is closely related to the development and progression of various malignancies, such as leukemia (21), chondrosarcoma (22), and prostate cancer $(23,24)$. In colorectal tumors, the transcription of Wnt target genes mediated by TCF7 is necessary for the initial activity of tumor stem cells (25). Studies concerning tumor resistance have shown that targeting $T C F 7$ by microRNA can inhibit the drug resistance in bladder and prostate cancer cells $(26,27)$. While the expression of TCF7 is significantly increased in CML imatinib-resistant cells, the role of TCF7 in CML imatinib-resistant cells is unclear.

In this study, we report that the expression of TCF7 is independent of BCR-ABL1 tyrosine kinase activity. TCF7 knockdown can inhibit the proliferation and restore imatinib sensitivity of imatinib-resistant cells. Furthermore, we found that TCF7 knockdown neutralized the upregulation trend of Wnt/ $\beta$-catenin and $\mathrm{ABC}$ transporter signaling pathways when imatinib-resistant cells were treated with imatinib and confirmed that TCF7 could transactivate $A B C C 2$ transcription by binding to the promoter region of $A B C C 2$. Our findings revealed that when $C M L$ imatinib-resistant cells are treated with imatinib, the $\mathrm{Wnt} / \beta$-catenin signaling pathway and $\mathrm{ABC}$ transporters play an essential role in the formation of imatinib resistance. Thus, targeting TCF7 to reduce the resistance of CML cells may be a viable treatment approach.

\section{Materials and methods}

Cell culture. The CML imatinib-resistant cell line K562/G01 was a kind gift from Professor Zhenlun Gu (Suzhou University, China). The CML cell line, KCL22 and K562, and acute myeloid leukemia (AML) cell lines, HL60 and NB4, were purchased from the Cell Bank of Shanghai Institute of Cell Biology, Chinese Academy of Science (Shanghai, China) and stored at our laboratory. All cell lines were maintained in RPMI-1640 medium (Gibco; Thermo Fisher Scientific, Inc.) supplemented with 10\% fetal bovine serum (FBS) (HyClone; GE Healthcare) and $1 \%$ penicillin-streptomycin (Beyotime Institute of Biotechnology) at $37^{\circ} \mathrm{C}$ in a $5 \% \mathrm{CO}_{2}$ atmosphere.

Reverse transcription-quantitative polymerase chain reaction $(R T-q P C R)$. The reagents and standard protocols used for the extraction of total RNA (RNAiso Plus), RNA reverse transcription into cDNA (PrimeScript ${ }^{\mathrm{TM}} \mathrm{RT}$ reagent Kit), and RT-qPCR (SYBR ${ }^{\circledR}$ Premix Ex Taq ${ }^{\mathrm{TM}}$ II) were obtained from Takara Bio. Inc. The thermocycling conditions were as follows: Initial denaturing step $\left(95^{\circ} \mathrm{C}, 3 \mathrm{~min}\right)$, followed by 40 cycles of denaturing $\left(95^{\circ} \mathrm{C}, 10 \mathrm{sec}\right)$, annealing $\left(55^{\circ} \mathrm{C}, 30 \mathrm{sec}\right)$ and extension $\left(72^{\circ} \mathrm{C}, 30 \mathrm{sec}\right)$. ACTB was used as an internal reference gene. The primers used for RT-qPCR are listed in Table I. Relative expression levels of mRNA were calculated using the $2^{-\Delta \Delta \mathrm{Cq}}$ method (28).

Western blot analysis. Western blot analysis was performed according to a standard protocol, as described previously (29). The following primary antibodies were used: Anti-ACTB (cat. no. TA09 purchased from ZSGB-BIO/now OriGene Technologies, Inc.), anti-ABCC2 (anti-MRP2) (cat. no. ab172630 purchased from Abcam, Inc.). Moreover, anti-BCR-ABL1 (cat. no. 2862), anti-p-BCR-ABL1 (cat. no. 2864), anti-CCND1 (cat. no. 2922), anti-CTNNB1 (cat. no. 9562), anti-PARP1 (cat. no. 9532), anti-STAT5 (cat. no. 25656), anti-p-STAT5 (cat. no. 4322) and anti-TCF7 (cat.no. 2203) were purchased from Cell Signaling Technology, Inc. (CST). The antibodies were used at a dilution of 1:1,000, except for anti-ACTB $(1: 2,000)$.

Lentiviral transduction. One scrambled negative control and two independent TCF7-targeting short hairpin RNAs (shRNAs) were cloned into the lentiviral vector GV248 (GeneChem, Shanghai, China) at the AgeI and EcoRI sites. The shRNA sequences are provided in Table II. K562/G01 and K562 cells in logarithmic growth phase were plated into 96-well plates (5,000 cells per well) and infected for $24 \mathrm{~h}$ with $50 \mathrm{IFU} / \mathrm{ml}$ lentivirus and $10 \mu \mathrm{g} / \mathrm{ml}$ polybrene, and then replaced with the normal medium and cultured for $48 \mathrm{~h}$. Next, puromycin was added to the plates at a final concentration of $2.0 \mu \mathrm{g} / \mathrm{ml}$ for reverse selection of the stable cell lines. Medium containing puromycin was replaced every 3 days. Transfection efficiency was monitored by inverted fluorescence microscopy and flow cytometry. After stable cell lines were produced, normal medium was used.

Immunofluorescence assay. Cells were smeared across a gelatin-coated slide to form a cell monolayer, and then the cell smear was fixed with methanol at $-20^{\circ} \mathrm{C}$ for $20 \mathrm{~min}$. The cell membranes were permeabilized using $1 \%$ Triton X100-PBS at $37^{\circ} \mathrm{C}$ for $15 \mathrm{~min}$. After washing the fixed slides three times in PBS, non-specific antigens were blocked with $10 \%$ goat serum at $37^{\circ} \mathrm{C}$ for $1 \mathrm{~h}$. The anti-TCF7 primary antibody (cat. no. 2203; CST) was diluted using $10 \%$ goat serum to $1: 400$, applied to the slide to cover the cell smear, and incubated overnight at $4^{\circ} \mathrm{C}$. The slides were washed three times in $400 \mu \mathrm{l}$ of wash buffer $(0.1 \%$ BSA in $1 \mathrm{X}$ PBS). The secondary antibody (goat anti-rabbit IgG $(\mathrm{H}+\mathrm{L})$ cross-adsorbed secondary antibody, cyanine 3; cat. no. A10520; Invitrogen; Thermo Fisher Scientific, Inc.) was diluted to 1:1,000, and $500 \mu \mathrm{l}$ was added to the smear and incubated at room temperature for $1 \mathrm{~h}$. Slides were rinsed twice in $500 \mu \mathrm{l}$ of wash buffer, and the nuclei were stained using DAPI (Beyotime Institute of Biotechnology) diluted with PBS to 1:1,000 for $5 \mathrm{~min}$. Slides were rinsed thrice with PBS and once with water. Finally, the smears with a drop of $70 \%$ glycerin were covered with coverglasses. The expression and distribution of fluorescence were observed 
Table I. Sequences used for RT-qPCR.

\begin{tabular}{ll}
\hline Primers & \multicolumn{1}{c}{ Sequences (5'-3') } \\
\hline $\begin{array}{l}\text { ACTB } \\
\text { Forward } \\
\text { Reverse }\end{array}$ & ACTTAGTTGCGTTACACCCTT \\
ABCC2 & \\
Forward & CCCTGCTGTTCGATATACCAATC \\
Reverse & TCGAGAGAATCCAGAATAGGGAC \\
BCR-ABL1 & \\
Forward & ATCCGTGGAGCTGCAGATG \\
Reverse & TTCCAACGAGCGGCTTCACT \\
CCND1 & \\
Forward & CATCCGCAAACACGC \\
Reverse & GGGCTCCTCAGGTTCA \\
TCF7 & \\
Forward & CTGGCTTCTACTCCCTGACCT \\
Reverse & ACCAGAACCTAGCATCAAGGA
\end{tabular}

ACTB, $\beta$-actin; ABCC2, ATP-binding cassette, sub-family $\mathrm{C}$ (CFTR/MRP), member 2; CCND1, cyclin D1; TCF7, transcription factor 7 .

using a fluorescence microscope (magnification, $\mathrm{x} 1,000$; Nikon Corporation).

Cell viability and colony formation assay. Cells were plated into 96-well flat-bottomed plates with $2 \times 10^{3}$ cells per well and treated with or without imatinib at the indicated concentrations. After cell culture for 12, 24, 48, 72, 96 and $120 \mathrm{~h}$, cell viability was determined using a CCK-8 kit (Solarbio, Inc.). For the colony formation assay, cells were seeded into 24-well flat-bottomed plates with 200 cells per well and grown in semi-solid medium containing $1.35 \%$ methylcellulose. After 9 days, the colonies were counted using an inverted fluorescence microscope (magnification, x40; Nikon Corporation).

Flow cytometric analysis. Cell cycle, apoptosis, cell counts, and GFP fluorescence were detected using flow cytometry (FCM). Cells were collected after treatment with or without imatinib at the indicated concentrations. To examine cell cycle dynamics, cells were subjected to serum starvation for $64 \mathrm{~h}$ to obtain synchronized cells, following which the serum supply was restored. Cell cycle status was monitored at 0,8 , 16,24 , and $32 \mathrm{~h}$. Cell cycle profiling was delineated by the FL2 fluorescence generated by the binding of propidium iodide (PI) to DNA, and the percentages of cells in different phases of the cell cycle were analyzed by FlowJo VX.0.7 software (FlowJo LLC). To detect cell apoptosis, the cells were double-labeled with Annexin V-APC and DAPI and measured by FCM according to the manufacturer's protocol. Given that flow cytometry records the volume of fluid and the fluorescence parameters of particles simultaneously, if the sample is thoroughly mixed, an accurate cell count and GFP fluorescence can be obtained.
RNA sequencing (RNA-seq) and bioinformatic analysis. Total RNAs from four groups of K562/G01 cells with scramble, imatinib, TCF7_KD, and TCF7_KD+imatinib treatment were extracted using an RNeasy kit (Qiagen, Inc.), and treated with DNase I (Qiagen Inc.). Imatinib was used at $1 \mu \mathrm{M}$ in K562/G01 cells. Shanghai Lifegenes Biotechnology performed RNA quantification, quality appraisal, library preparation, and sequencing. Raw data (raw reads) of fastq format were firstly processed through in-house perl scripts. HTSeq v0.6.1 (https://htseq.readthedocs.io/en/master/) was used to count the read number mapped to each gene. Gene fragment per kilobase of exon per million reads (FPKMs) were computed by summing the FPKMs of transcripts in each gene group. Gene set enrichment analysis (GSEA) (30) software v4.0.3 was used to analyze RNA-seq data. Cytoscape software v3.6.0 was used to visualize the GSEA reasults (31). The cut-offs of differentially expressed genes (DEGs) were set as $\log _{2}$ (fold change) $\mid>0.5$ and FPKM $>0.3$, and consequently 1,034 DEGs were obtained. The Gene Ontology (GO) enrichment analysis of DEGs was executed using the $\mathrm{R}$ package clusterProfiler v3.11.1 (32). All sequencing data were used in principal component analysis (PCA). Gene expression heatmaps and PCA were performed using the web tool ClustVis (https://biit.cs.ut. ee/clustvis/) (33). Three-dimensional plots were produced using the $\mathrm{R}$ package lattice v0.20-38. Venn diagrams were calculated and drawn using a web tool (http://bioinformatics. psb.ugent.be/webtools/Venn/). The visualization of RNA-seq and chromatin immunoprecipitation sequence (ChIP-seq) data were performed using Integrative Genomics Viewer software v2.6.3 (http://software.broadinstitute.org/software/igv/) (34).

Chromatin immunoprecipitation-qPCR (ChIP-qPCR). Chromatin immunoprecipitation kit (cat. no. 9005) was purchased from CST, and anti-TCF7 (cat. no. bs1987) was purchased from Bioword, Inc. The ChIP experiment was performed according to the manufacturer's instructions. Immunoprecipitated DNA fragments were purified by phenol extraction and then quantified by qPCR. The primer sequences are listed in Table III.

Statistical analysis. Results of column charts and line charts are presented as the mean \pm standard deviation and were analyzed by GraphPad (Prism 5) (GraphPad Software, Inc.). Each experiment was performed at least three times. Statistical analysis were performed using the Student's t-test or one-way analysis of variance (ANOVA) with Tukey's post hoc test. Statistical significance levels were as follows: ${ }^{*} \mathrm{P}<0.05$, ${ }^{* *} \mathrm{P}<0.01,{ }^{* * *} \mathrm{P}<0.001$ (as shown in the figure legends with the respective symbols).

\section{Results}

TCF7 is highly expressed in CML imatinib-resistant cells and independent of tyrosine kinase activity of $B C R-A B L 1$. In the chronic phase, BCR-ABL1 is recognized as an effective target for CML treatment, but other targets need to be explored when resistance develops. We first investigated gene expression microarray datasets GSE47927 (35) and GSE4170 (36), and results of the analysis revealed that the Wnt/ $\beta$-catenin signaling pathway was activated in all phases of CML and in 
Table II. shRNA sequences used for the scramble and TCF7 knockdown.

shRNA

Sequences $\left(5^{\prime}>3^{\prime}\right)$

Scramble-F

Scramble-R

TCF7-KD1F

TCF7-KD1R

TCF7-KD2F

TCF7-KD2R
CCGGTTCTCCGAACGTGTCACGTTTCAAGAGAACGTGACACGTTCGGAGAATTTTTG AATTCAAAAATTCTCCGAACGTGTCACGTTCTCTTGAAACGTGACACGTTCGGAGAA CCGGCAACTCTCTCTCTACGAACATCTCGAGATGTTCGTAGAGAGAGAGTTGTTTTTG AATTCAAAAACAACTCTCTCTCTACGAACATCTCGAGATGTTCGTAGAGAGAGAGTTG CCGGGCGGGACAACTACGGGAAGAACTCGAGTTCTTCCCGTAGTTGTCCCGCTTTTTG AATTCAAAAAGCGGGACAACTACGGGAAGAACTCGAGTTCTTCCCGTAGTTGTCCCGC

F, forward; R, reverse; TCF7, transcription factor 7. The loop sequence is shown in bold and the stem sequence is underlined.

Table III. Sequences used for RT-qPCR.

\begin{tabular}{lc}
\hline Primers & \multicolumn{1}{c}{ Sequences (5'-3') } \\
\hline $\begin{array}{l}\text { Negative control } \\
\text { Forward }\end{array}$ & \\
Reverse & TTGGAATCATACAGTATGTAGCC \\
pmABCC2 & CTATTGAGCCATGAAAAGATGTG \\
Forward & ACTGTGCACTCTTGATTTGTTGG \\
Reverse & AGGAGTGGCCATACATAAAAGG \\
\hline
\end{tabular}

the event of imatinib resistance (Fig. 1A). TCF7 expression was higher in blast crisis and imatinib-resistant samples, when compared with chronic phase and imatinib-sensitive samples, respectively. (Fig. 1B and $\mathrm{C}$ ). Futhermore, we analyzed dataset GSE76312 (37) and the results were consistent with the results in GSE47927 and GSE4170 (Fig. S1E). To assess the expression of TCF7 in leukemia cell lines, we tested CML cell lines (K562, K562/G01 and KCL22), and acute myeloid leukemia (AML) cell lines (HL60 and NB4) using RT-qPCR and western blot analyses. The results showed that TCF7 was significantly overexpressed in blast crisis (K562, KCL22) and imatinib-resistent (K562/G01) CML cell lines (Fig. 1D and E). The K562/G01 cell line is evolved from the K562 cell line by long-term treatment with imatinib, and it has the characteristic of imatinib resistance.

To investigate whether the expression of TCF7 in imatinib-resistant cells was affected by the activity of BCR-ABL1, K562/G01 cells were treated with imatinib at concentrations of 1 and $5 \mu \mathrm{M}$, and the mRNA expression levels of $B C R-A B L 1, T C F 7$, and $C C N D 1$ were detected using RT-qPCR. Next, the activation status of BCR-ABL1, STAT5, and the protein expression levels of BCR-ABL1, STAT5, PARP, CCND1, and TCF7 were detected using western blot analysis. In response to imatinib, the results of RT-qPCR showed that there was no significant change in the mRNA expression of TCF7 and BCR-ABL1 except CCNDI (Fig. 1F). Consistent with this, the results of western blot analysis showed that the expression of CCND1 was gradually decreased while the expression of BCR-ABL1, STAT5, and TCF7 did not change. In addition, when cells were exposed to a high concentration of imatinib $(5 \mu \mathrm{M})$, PARP1 began cleaving into fragments, and the activity of BCR-ABL1 and its downstream target STAT5, in the form of phosphorylated (p)-BCR-ABL1 and p-STAT5, were significantly inhibited (Fig. 1G). These results indicate that BCR-ABL1 activity has no significant effect on the regulation of TCF7. In addition, changes in cell morphology suggested that increasing drug concentrations led to increased death of imatinib-resistant cells to a certain extent (Fig. $1 \mathrm{H})$.

TCF7 knockdown in K562 and K562/G01 cells. K562 and K562/G01 cells were transduced with two LV-TCF7-RNAi recombinant lentiviruses and one LV-Scramble lentivirus, respectively. After puromycin treatment, stably transduced cells were obtained. The results of flow cytometry indicated that transduction efficiency was close to $100 \%$ (Fig. 2A). Next, The RT-qPCR results showed that the knockdown efficiencies of the designed shRNAs were all greater than $80 \%$ (Fig. 2B). Furthermore, the western blot results confirmed the results of the RT-qPCR (Fig. 2C). In addition, immunofluorescence assays results visualized TCF7 expression changes and nuclear localization in K562/G01 cells (Fig. 2D).

TCF7 knockdown inhibits the proliferation of K562/G01 cells. To test the effect of TCF7 knockdown on the proliferation of K562 and K562/G01 cells, we first performed a cell viability test. The results showed that the cell viability of K562/G01cells was significantly inhibited in the TCF7_KD groups compared with the Scramble groups (Fig. 3A). Interestingly, in contrast to K562 cells, the inhibition of cell viability caused by TCF7 knockdown was more pronounced in the K562/G01 cells (Fig. 3B). In addition, cell count results showed a lower cell counts in the TCF7_KD groups of K562/G01 cells (Fig. 3F).

We further performed cell cycle assays. The results showed that compared with the Scramble group, the TCF7_KD groups consisted of a higher proportion of $\mathrm{G} 0 / \mathrm{G} 1$ phase cells, and less $\mathrm{S}+\mathrm{G} 2 / \mathrm{M}$ phase cells in the K562/G01 cells but not in the K562 cells (Fig. 3C and D). In addition, the TCF7_KD groups showed a significant increase in the number of sub-G1 phase cells (Fig. 3C). The serum starvation release test showed that after restoring serum to the serum-free medium, cells in the TCF7_KD group re-entered the cell cycle more slowly (Fig. 3E). The above results suggest that TCF7 knockdown led to an inhibition of proliferation, particularly in the CML imatinib-resistant cells. 
A

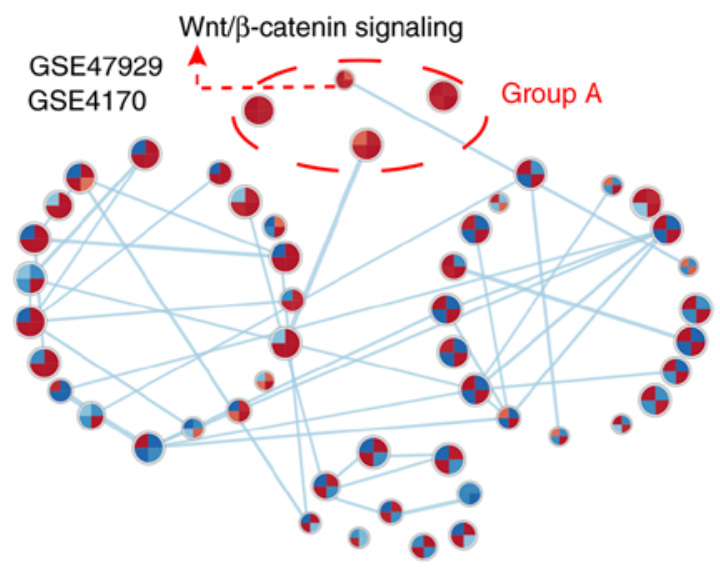

NES

IMR vs IMS AP vs Normal

CP vs Normal - BC vs Normal

C

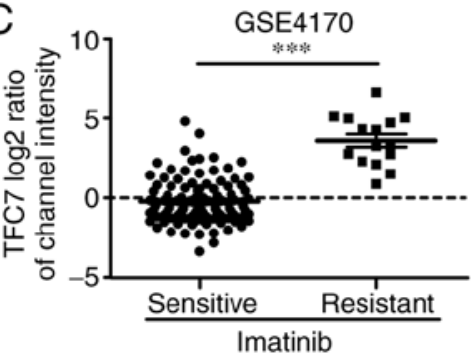

F

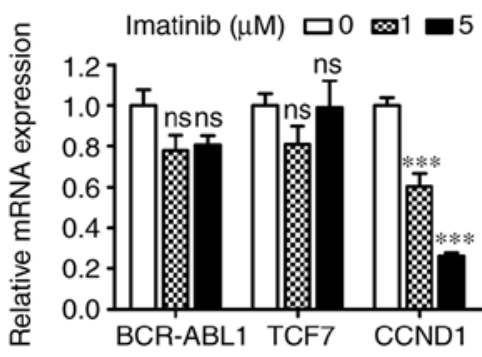

B

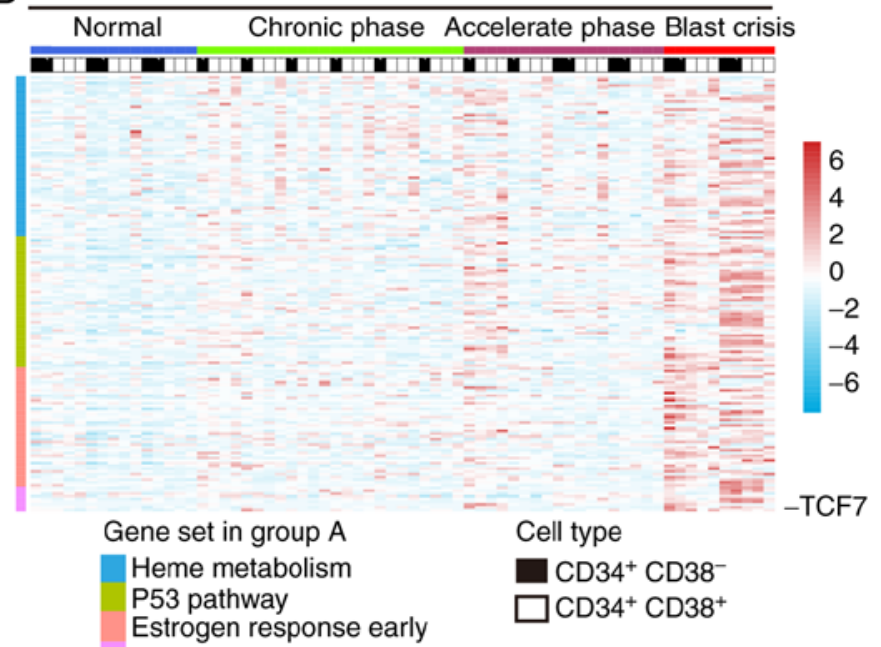

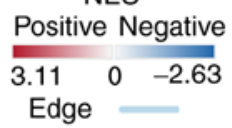

D

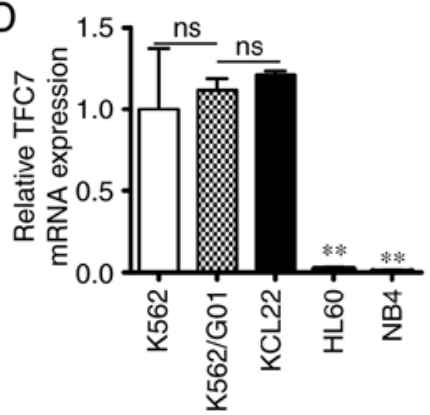

G

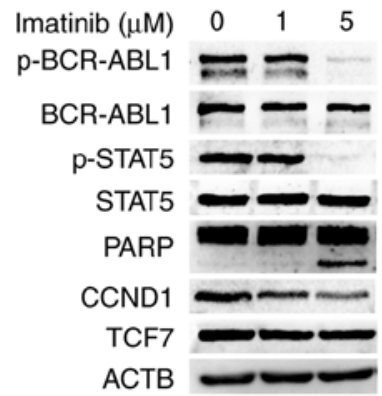

E

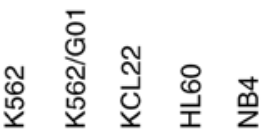

BCR-ABL1 - $\cdots$

TCF7 - -

ACTB

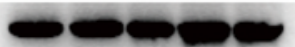

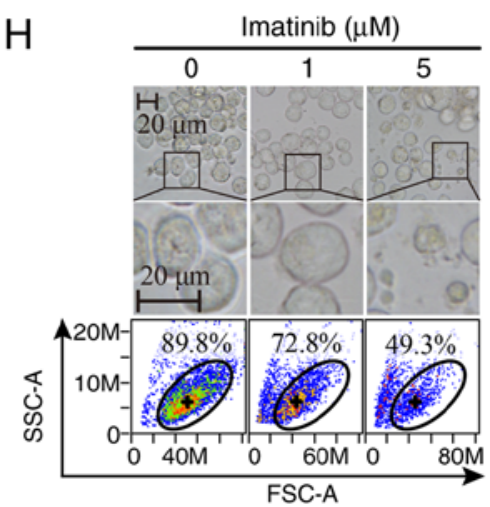

Figure 1. Expression of TCF7 in CML and its relationship with BCR-ABL1. (A) Cytoscape visualizes the changes in signaling pathways during progression (GSE47927) and IM resistance (GSE4170) of CML. IMR, imatinib resistant; IMS, imatinib sensitive; BC, blast crisis; CP, chronic phase; AP, accelerated phase. (B) Heatmap showing expression levels of 727 genes in group A signaling pathway in the GSE47927 dataset. (C) Grouped scatter plot showing levels of TCF7 expression in CML cells from imatinib-sensitive $(\mathrm{n}=104)$ and imatinib-resistant $(\mathrm{n}=15)$ patient samples in the GSE4170 dataset. (D and E) Expression of TCF7 mRNA (B) and protein (C) in CML cell lines, K562, K562/G01 and KCL22, and AML cell lines, HL60, and NB4. (F) RT-qPCR analysis showing mRNA expression of $B C R-A B L 1, T C F 7$, and $C C N D 1$. (G) Western blot analysis showing protein expression of BCR-ABL1 and STAT5, and the expression of TCF7, CCND1, and PARP. (H) Light microscopic images and flow cytometry scatter plots showing K562/G01 morphological changes under increasing concentrations of imatinib treatment. Two-tailed Student's t-test was used for C, one-way ANOVA with Tukey's post hoc test were performed for D and E. ${ }^{* *} \mathrm{P}<0.01,{ }^{* * *} \mathrm{P}<0.001$; ns, not significant. TCF7, transcription factor 7; CML, chronic myeloid leukemia; AML, acute myeloid leukemia; CCND1, cyclin D1; STAT5, signal transducer and activator of transcription 5; PARP, poly(ADP) ribose polymerase; ACTB, $\beta$-actin; p-, phosphorylated.

TCF7 knockdown improves the sensitivity of K562/G01 cells to imatinib. Compared with the parental K562 cells, K562/G01 cells exhibit significant resistance to imatinib, and previous reports have shown that TCF7 may affect the drug resistance of tumor cells $(26,27)$. Therefore, we investigated whether $T C F 7$ knockdown can increase imatinib sensitivity in CML cells. The results of the drug sensitivity test showed that, in K562/G01 cells, the half maximal inhibitory concentration $\left(\mathrm{IC}_{50}\right)$ value of the Scramble group was $8.3 \mu \mathrm{M}$, while the
$\mathrm{IC}_{50}$ value of the TCF7_KD group was $4.7 \mu \mathrm{M}$ (Fig. 4A and B). In comparison, no significant change in imatinib sensitivity was observed in K562 cells (Fig. 4C and D). Cell viability and GFP-positive cell count results showed that, in K562/G01 cells, cell proliferation in the TCF7_KD group was inhibited while imatinib concentration increased from 0.5 to $1.0 \mu \mathrm{M}$, but not in the Scramble group (Fig. 4E and F). In addition, the colony formation assay showed that TCF7 knockdown combined with imatinib could significantly inhibit the colony 
A

- Scramble $=$ TCF7_KD_\#1 - TCF7_KD_\#2
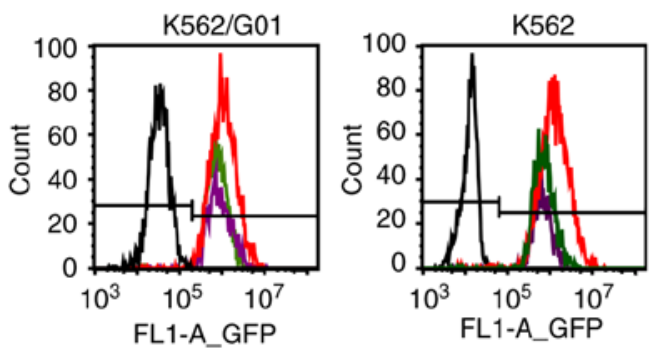

B

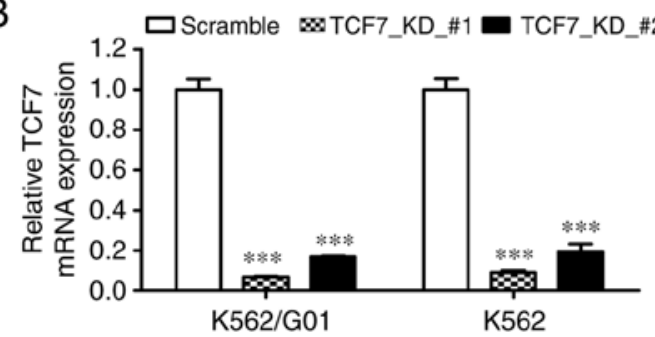

D

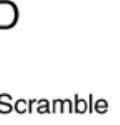
TCF7

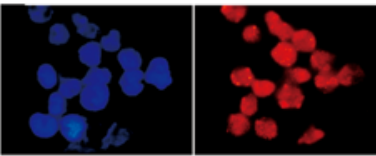

Merged Enlarged

Scramble

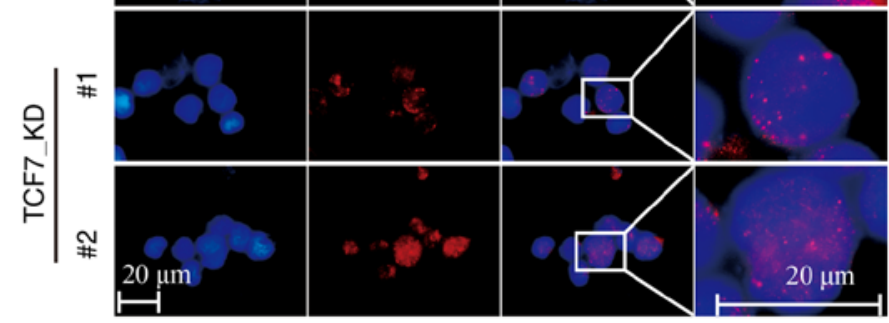

C
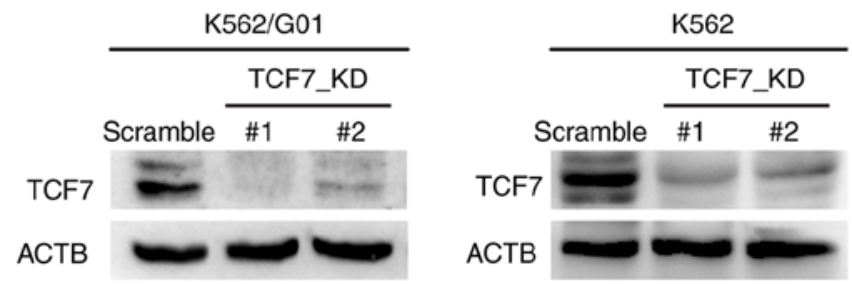

Figure 2. TCF7 knockdown in CML K562 and K562/G01 cells. (A) Transfection efficiency of K562/G01 cells was examined by flow cytometry. (B and C) Efficiency of TCF7 knockdown is demonstrated at the mRNA (B) and protein (C) levels by RT-qPCR and western blot analysis, respectively. (D) Immunofluorescence microscopy showing the expression and localization of TCF7 in K562/G01 cells. One-way ANOVA with Tukey's post hoc test was performed for $\mathrm{C} .{ }^{* * *} \mathrm{P}<0.001$. TCF7, transcription factor 7; CML, chronic myeloid leukemia.

formation rate of $\mathrm{K} 562 / \mathrm{G} 01$ cells (Fig. $4 \mathrm{G}$ and $\mathrm{H}$ ). The above results showed that $T C F 7$ knockdown can increase imatinib sensitivity in imatinib-resistant cells and that TCF7 knockdown combined with imatinib can inhibit imatinib-resistant cells more effectively.

Principal component analysis (PCA) and Gene Ontology (GO) enrichment analysis of RNA-seq data. To investigate why TCF7 knockdown affects proliferation and drug resistance of K562/G01 cells, we obtained RNA-seq data (GSE152220) from the Scramble, TCF7_KD, Scramble+Imatinib, and TCF7_KD+Imatinib groups. PCA result showed that the combination group underwent more intervention on the transcriptome (Fig. 5A). GO enrichment analysis showed that differentially expressed genes (DEGs) in the TCF7_KD group were particularly enriched in the term of leukocyte proliferation (Fig. 5B). These results explain our findings that TCF7 knockdown can affect proliferation of K562/G01 cells. Next, the GO Chord plot lists the core genes such as $A B C C 2$ (Fig. 5C). ABCC2 is a member of the ATP-binding cassette (ABC) transporter superfamily, and this family is often associated with multidrug resistance of tumors $(38,39)$.

TCF7 knockdown neutralizes upregulated ABC transporters and Wnt/ $\beta$-catenin signaling during imatinib treatment. Given the critical role of the ABC transporter family in chemotherapy resistance of tumor cells $(40,41)$, we used RNA-seq data to analyze the changes in the $\mathrm{ABC}$ transporter signaling pathway in CML cells. Using single-cell RNA-seq data of 1,062 BCR-ABL1+ ${ }^{+}$LSCs from the GSE76312 dataset (37) for TCF7 single-gene GSEA analysis, it was found that the expression of $T C F 7$ was positively correlated with the gene expression of $\mathrm{ABC}$ transporter signaling pathway (Fig. S1A).
We subsequently set the Scramble group as the control and compared it with the TCF7_KD, Scramble+Imatinib, and TCF7_KD+Imatinib groups using GSEA analysis. The results showed that although the ABC transporter signaling pathway was upregulated in $\mathrm{K} 562 / \mathrm{G} 01$ cells following imatinib treatment, TCF 7 knockdown caused its expression to be downregulated. When imatinib was used after TCF7 knockdown, the upregulated trend of the $\mathrm{ABC}$ transporter signaling pathway was neutralized (Fig. S1A).

Furthermore, we analyzed the Wnt (Fig. S1B) and Wnt/ $\beta$-catenin signaling pathway (Fig. 6A), and the results showed that the trend in the changes in each group was consistent with the changes in $\mathrm{ABC}$ transporters. The expression levels of core enrichment genes representing ABC transporters and Wnt signaling pathway in the TCF7_KD group are displayed in the heatmap (Fig. 6B). Next, the expression levels of $\mathrm{ABCC} 2$ and CCND1 were verified by RT-qPCR and western blot analysis. The results confirmed that the expression levels of ABCC2 and CCND1 were decreased when TCF7 was silenced in the CML imatinib-resistant cells (Fig. 6C and D). In addition, the expression level of CTNNB1, a key protein of the canonical Wnt signaling pathway, was also decreased (Fig. 6C).

ABCC2 is a TCF 7 target gene. As a transcription factor, TCF7 promotes the transcription of many genes by binding to motifs. TCF7 target genes were calculated from ChIP-seq data in the GTRD database (42) and collated into a gene set, named TCF7_targets. We then analyzed the single-cell RNA-seq data of BCR-ABL1 ${ }^{+}$LSCs in the dataset GSE76312 (37) and our four groups of RNA-seq dataset GSE152220. The results showed that the expression of TCF7 was positively correlated with TCF7_targets gene set in BCR-ABL1 ${ }^{+}$LSCs cells 
A

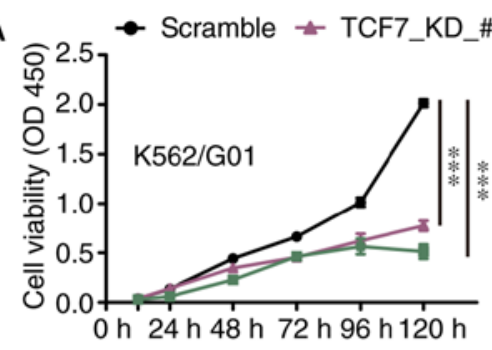

B

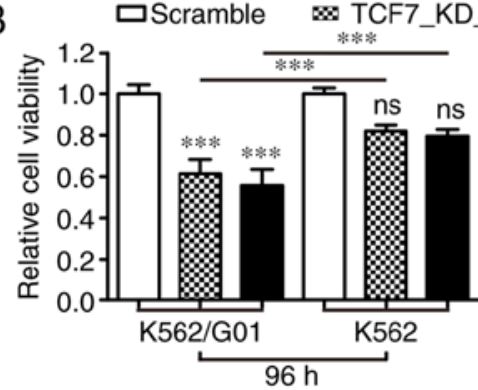

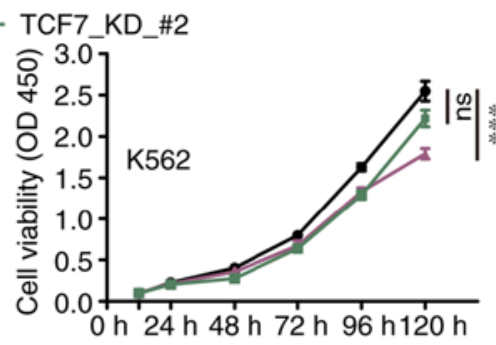

TCF7_KD_\#2

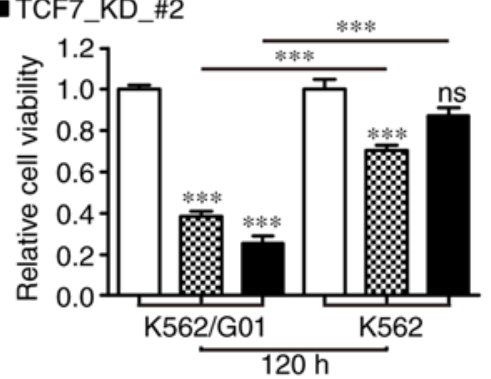

C
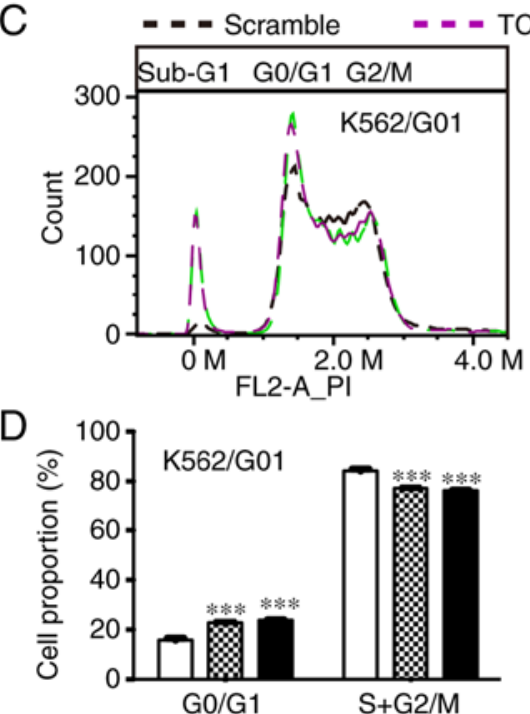
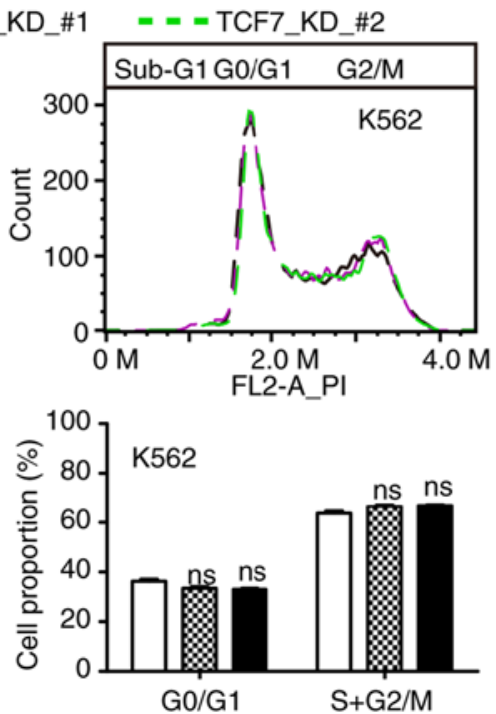

E
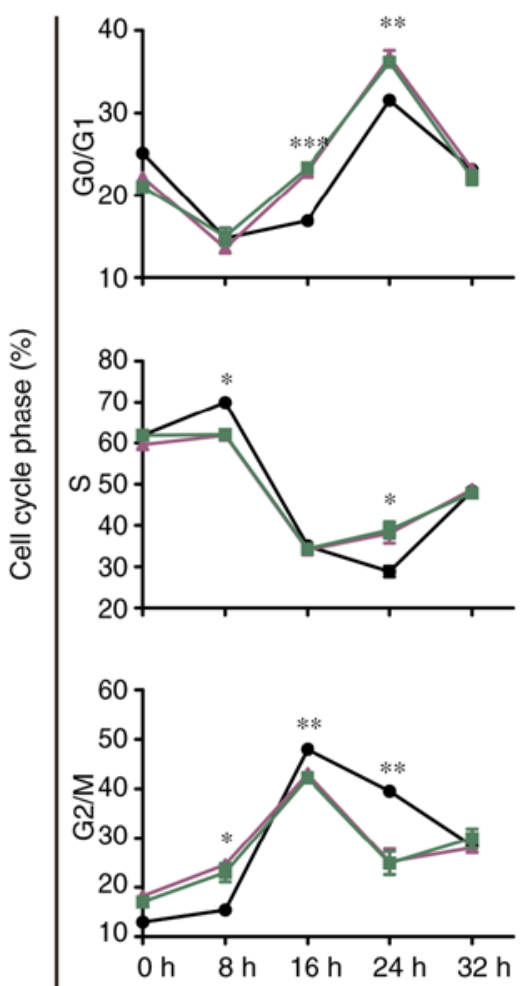

K562/G01

- Scramble

- TCF7_KD_\#1

- TCF7_KD_\#2

F

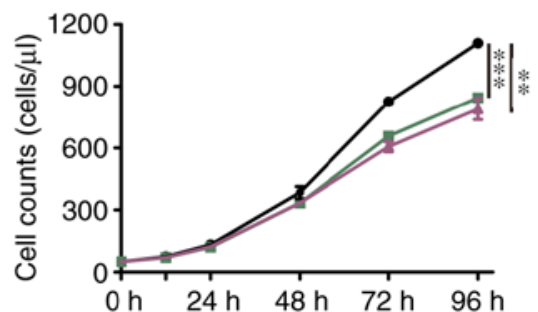

Figure 3. TCF7 knockdown reduces the proliferation and survival of CML K562/G01 cells. (A and B) CCK-8 assays were used to detect the cell viability of the Scramble and TCF7_KD groups at 12, 24, 48, 72, 96 and $120 \mathrm{~h}$. (C and D) Cell cycle distribution of the Scramble and TCF7_KD groups during the logarithmic growth phase. (E) Cell cycle distribution of the Scramble and TCF7_KD groups following serum starvation and release at 0, 8, 16, 24, and 32 h. (F) Flow cytometry cell counts of the Scramble and TCF7_KD groups at 0,12, 24, 48, 72, and $96 \mathrm{~h}$. One-way ANOVA with Tukey's post hoc test were performed. ${ }^{*} \mathrm{P}<0.05,{ }^{* *} \mathrm{P}<0.01,{ }^{* * *} \mathrm{P}<0.001$. TCF7, transcription factor 7; CML, chronic myeloid leukemia; KD, knockdown.

(Fig. S1C). On the other hand, TCF7 knockdown resulted in its downregulation in K562/G01 cells (Fig. S1C).

$A B C C 2$ was identified by screening a intersection of four gene, namely TCF7_targets, TCF7 correlated core enrichment genes, TCF7_KD downregulated genes, and ABC transporters (Fig. S1D). Integrative genomics viewer (IGV) was used to visualize the processed ChIP-seq data ENCFF476IUK, and it was found that TCF7 had a binding peak in the promoter region of $A B C C 2$ (Fig. 6E). In addition, by integrating our RNA-seq data into IGV, it can be seen intuitively that the transcription level of $A B C C 2$ was lower in the TCF7_KD group compared with the Scramble group (Fig. 6E). Furthermore, ChIP-qPCR results showed that TCF7 was recruited to the promoter region of $A B C C 2$ in $\mathrm{K} 562 / \mathrm{G01}$ cells (Fig. 6F). These results indicate that TCF7 is a direct transcriptional regulator of $A B C C 2$ in K562/G01 cells. In summary, the roles of TCF7 and imatinib in CML imatinib-resistant cells are shown in a graphical abstract (Fig. 6G).

\section{Discussion}

Since the application of first-generation tyrosine kinase inhibitor (TKI), imatinib, in clinical practice, the problem of drug resistance with complex mechanisms has emerged. TKIs can effectively solve the drug resistance caused by BCR-ABL1 point mutations (6), while BCR-ABL1-independent drug resistance has become a new urgent concern. The results of the present study indicate that the expression of transcription factor 7 (TCF7) is independent of the tyrosine kinase activity of BCR-ABL1 in imatinib-resistant cells. TCF7 knockdown can significantly inhibit the proliferation and improve imatinib sensitivity of imatinib-resistant cells. In addition, GSEA analysis indicated that $\mathrm{ABC}$ transporters and the Wnt/ $\beta$-catenin signaling pathways are upregulated during imatinib treatment in imatinib-resistant cells, while TCF7 knockdown can neutralize this trend. 

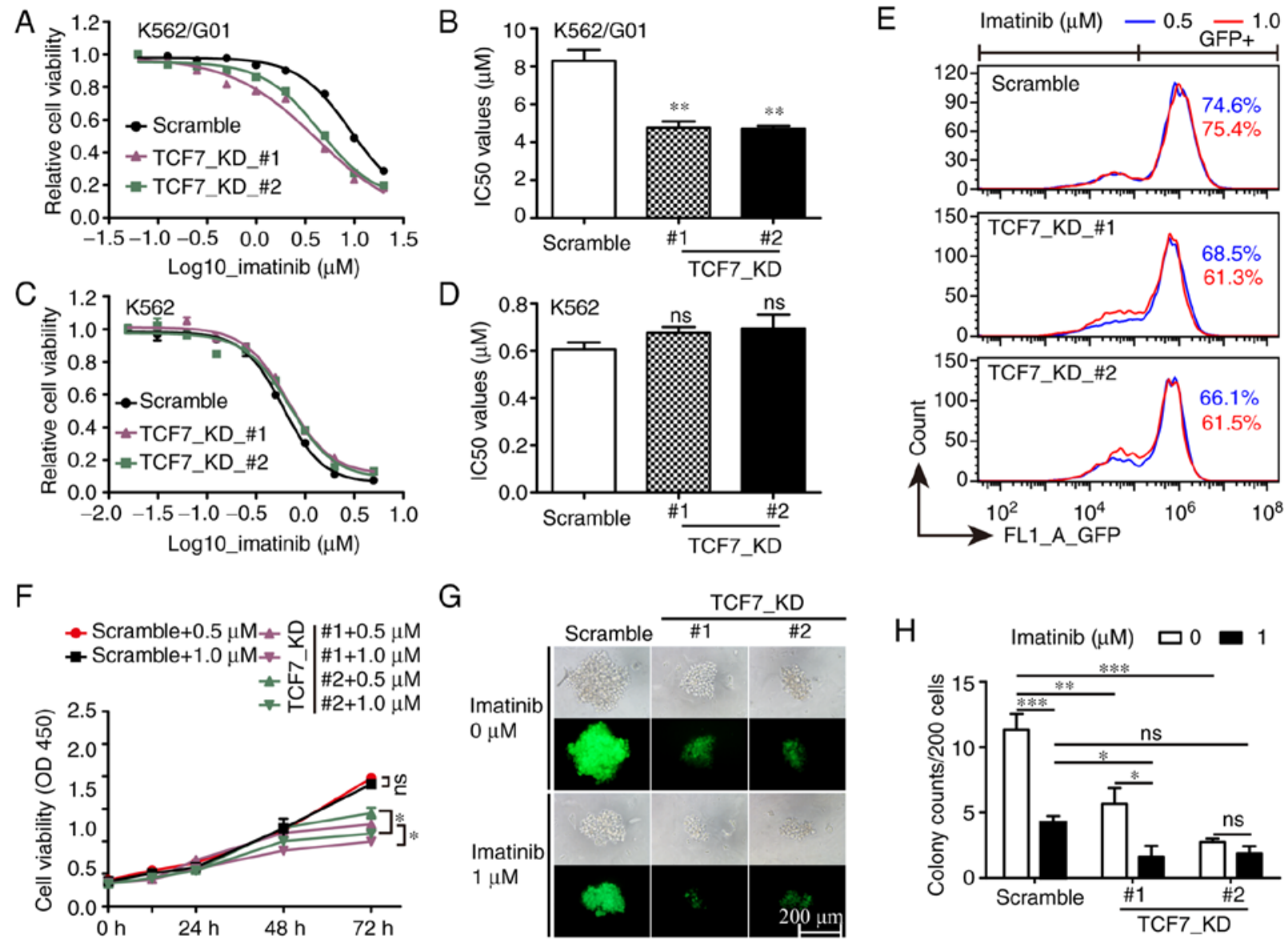

Figure 4. TCF7 knockdown restores the sensitivity of K562/G01 cells to imatinib. (A and C) Drug sensitivity curves showing cell viability of the Scramble and TCF7_KD groups cells after $72 \mathrm{~h}$ of treatment with a series of concentrations of imatinib. (B and D) Histogram showing the $\mathrm{IC}_{50}$ values. (E) The ratio of GFP-positive cells was measured to identify the survival status of the cell population exposed to imatinib in K562/G01 cells. (F) Cell viability of K562/G01 cells treated with imatinib at 0.5 and $1.0 \mu \mathrm{M}$. (G and H) Colony forming assays of Scramble and TCF7_KD groups of K562/G01 cells treated with 0 and $1.0 \mu \mathrm{M}$ imatinib for $24 \mathrm{~h}$ followed by visualization using fluorescence microscopy. Fluorescence intensity directly shows the viability of the cells in the colonies. Colony counts are displayed in the histogram. One-way ANOVA with Tukey's post hoc test was performed for B, D, F and $\mathrm{H} .{ }^{*} \mathrm{P}<0.05,{ }^{* *} \mathrm{P}<0.01,{ }^{* * *} \mathrm{P}<0.001$. ns, not significant. TCF7, transcription factor 7; CML, chronic myeloid leukemia; KD, knockdown.

Wnt signaling is involved in regulating embryonic development and adult tissue homeostasis, and components of Wnt signaling pathway aberrant regulation are closely linked to the development of various tumors (43). Genome-wide ChIP-Seq results show that the TCF/LEF family is the most critical transcription factor group mediating Wnt/ $\beta$-catenin signaling function (44). Previous studies have shown that overexpression of TCF7 is often associated with disease progression and poor prognosis in nasopharyngeal cancer (45), gastric cancer (46), and astroglioma (47). Consistent with these finding, TCF7 expression was significantly increased in imatinib-resistant patients compared with imatinib-sensitive patients. These results indicate that TCF7 may play a vital role in the development of drug resistance in chronic myeloid leukemia (CML) cells. An increasing number of studies have shown that replacing or combining other targets to conquer leukemia drug resistance has become a feasible strategy $(48,49)$. In the present study, even when BCR-ABL1 activity was inhibited entirely, TCF7 expression was not significantly altered, indicating that TCF7 expression is BCR-ABL1-independent and combined targets of TCF7 and BCR-ABL1 may have a synergistic effect on the inhibition of CML imatinib-resistant cells.
In bladder and prostate cancers, targeting TCF7 can increase the sensitivity of cancer cells to chemotherapy $(26,27)$. In CML, silencing of $\beta$-catenin or inhibition of $\beta$-catenin with the small molecule drug C 82 can also have the same effect of reducing drug resistance (10). Consistent with the above studies, our results showed that knockdown of TCF7 resulted in impaired cell proliferation and enhancement of imatinib sensitivity in CML imatinib-resistant cells. Thus, combined target therapy can more effectively inhibit the viability of imatinib-resistant cells. Interestingly, although there are four members of the TCF/LEF family that interact with $\beta$-catenin in the Wnt signaling pathway, the fact that TCF7 knockdown can function alone suggests that the Wnt/ $\beta$-catenin/TCF7 signaling axis is involved in the initiation of drug resistance during TKI treatment.

The molecular events specifically affected by $T C F 7$ knockdown are the vital clues revealing the mechanism of phenotype generation. In a previous report, $\mathrm{ABCC} 2$ overexpression conferred tumor cell resistance to multiple chemotherapeutic drugs such as vincristine, cisplatin, etoposide, doxorubicin, and methotrexate (38). Previous studies have shown that the $A B C C 2$ $\mathrm{T}_{-24} \mathrm{G}_{1249} \mathrm{~T}_{3972}$ haplotype is related to imatinib resistance (50). Its expression is relatively higher in imatinib-resistant patients 
A

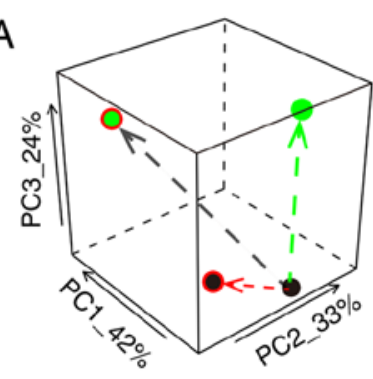

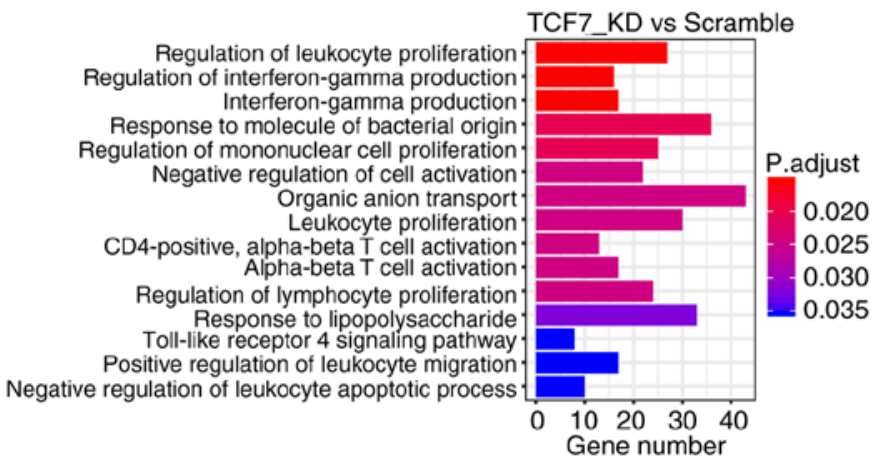

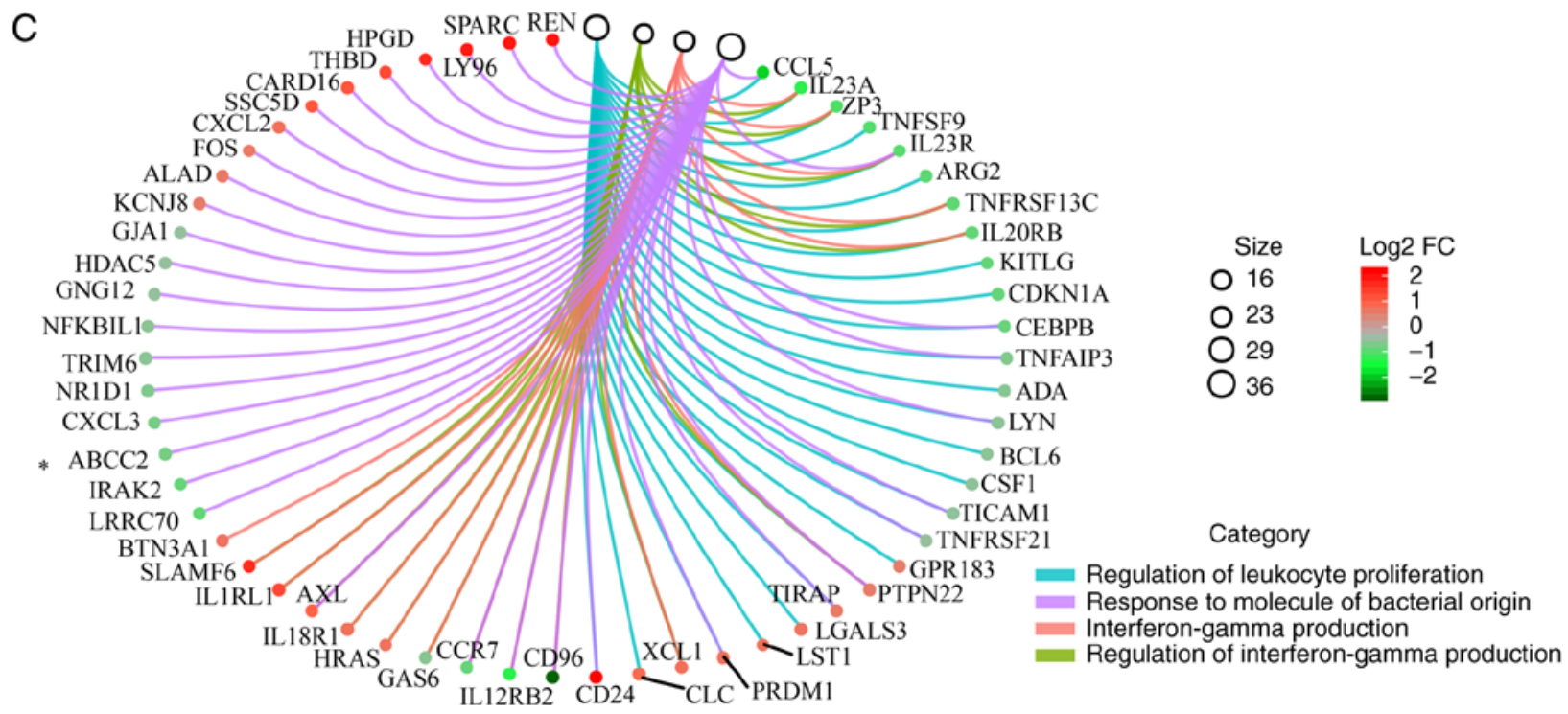

Figure 5. Principal component analysis (PCA) and Gene Ontology (GO) enrichment analysis of RNA-seq data. (A) PCA analysis of four RNA-seq data groups of K562/G01 cells. (B) GO enrichment analysis of DEGs. A p.adjust-value $<0.05$ was regarded as significant. (C) GOChord plot of the core genes. DEGs, differentially expressed genes. TCF7, transcription factor 7; KD, knockdown.

compared to imatinib-sensitive patients, and its knockdown can restore the sensitivity of resistant cells to imatinib (18). The above data indicate that $\mathrm{ABCC} 2$ contributes to $\mathrm{CML}$ resistance. In this study, we found that TCF7 is recruited to the promoter region of $A B C C 2$ and transactivates $A B C C 2$ transcription. Furthermore, $T C F 7$ knockdown can weaken the intensity of $\mathrm{ABC}$ transporter signaling.

Interestingly, a recent study by Trojani et al (51) demonstrated that long-term use of second-generation TKI (nilotinib) in $\mathrm{CML}$ patients can induce the upregulation of $\mathrm{ABC}$ transporters (ABCC4, ABCC5, ABCD3) in bone marrow $\mathrm{CD}_{3} 4^{+} /$lin $^{-}$cells. Another independent study by Mehrvar et al (52) demonstrated the changes in expression pattern of ABCC transporters in peripheral blood leukocytes of patients with acute lymphoblastic leukemia (ALL) recurrence. In particular, the expression of ABCC2 was significantly increased and could be used as a predictor of ALL hematologic relapse. Based on the abovementioned studies, we can speculate regarding the following two points: One is that under long-term chemotherapy, ABC transporters in leukemia cells will be abnormally expressed, and the second is that the abnormal expression of $\mathrm{ABC}$ transporters will be related to leukemia hematologic relapse. In CML, the therapeutic regimen involves TKI administration, and the basis for relapse is TKI resistance. Thus, TKIs can lead to abnormal expression of $\mathrm{ABC}$ transporters, which in turn can lead to the generation of TKI resistance in CML cells. However, the samples consisted of bone marrow CD34 ${ }^{+} /$lin $^{-}$ cells and peripheral blood leukocytes used in the previous studies. Because the proportion of leukemia cells is unknown, it is ambiguous whether the appearance of abnormal indicators originates from leukemia cells. Our study has answered this question. When imatinib-resistant cells were treated with imatinib, the intensity of $\mathrm{ABC}$ transporter signaling was significantly increased. More importantly, in BCR-ABL1 ${ }^{+}$ LSCs, TCF7 expression was positively correlated with ABC transporters. TCF7 knockdown can lead to its downregulation, which is contrary to the effect of imatinib on imatinib-resistant cells. In addition, we found that imatinib induced the upregulation of the Wnt/ $\beta$-catenin signaling pathway in imatinib-resistant cells, and TCF7 knockdown could partially offset this trend. To the best of our knowledge, this is the first study to show these effects of TKI and TCF7 on $\mathrm{Wnt} / \beta$-catenin and $\mathrm{ABC}$ transporter signaling pathways in imatinib-resistant cells.

One limitation of this study is that RNA-seq data at the cell population level cannot characterize the various subsets contained in the whole tumor. Moreover, even when imatinib-resistant cells are exposed to high concentrations of imatinib, some cells could still survive, which will become a major hidden danger that blocks CML patients to achieve full recovery. A deep understanding of the existence and 
A HALLMARK_WNT_BETA_CATENIN_SIGNALING
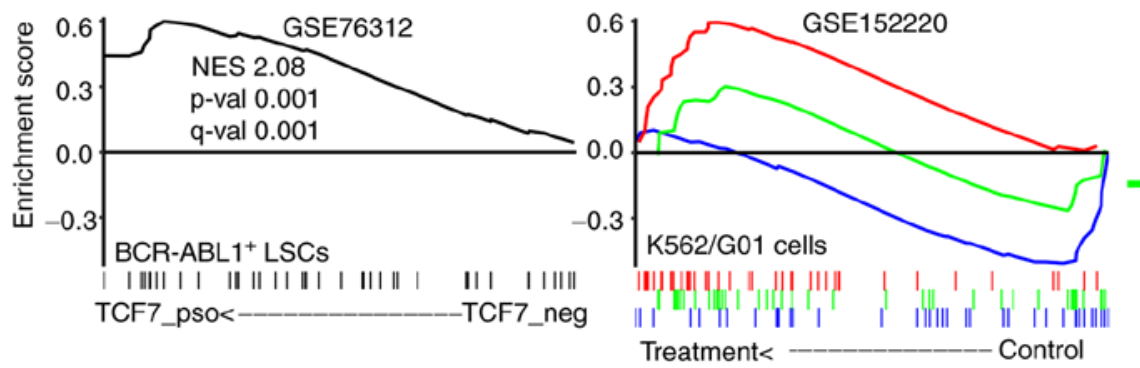

NES p-val q-val

- Imatinib 1.550 .0100 .054

$=$ TCF7_KD+imatinib 0.780 .8570 .919

- TCF7_KD-1.440.0340.061

B

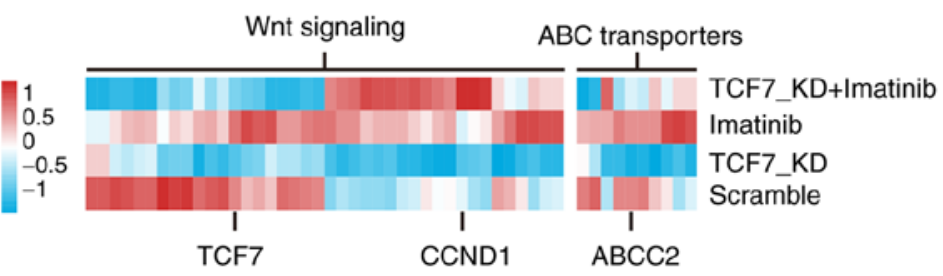

C

K562/G01

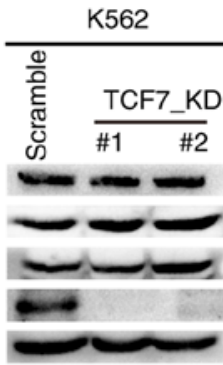

D

$\square$ Scramble $\quad *$ TCF7_KD1

TCF7_KD2
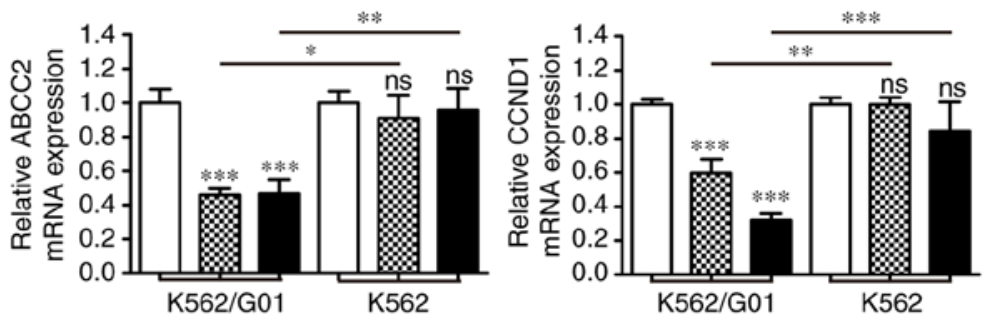

$\mathrm{E}$

chr10:99, 781, 157-99,854,751

ABCC2

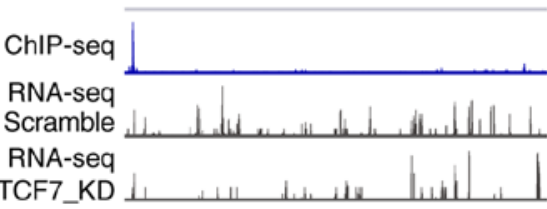

$\mathrm{F}$

$\square$ NC probe $\square$ pmABCC2 probe

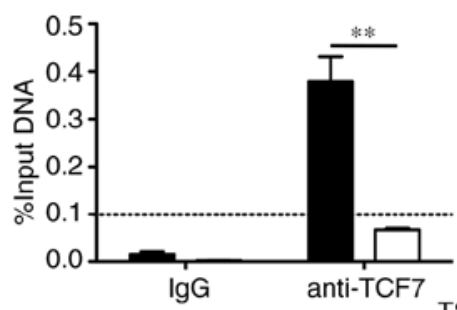

$\mathrm{G}$
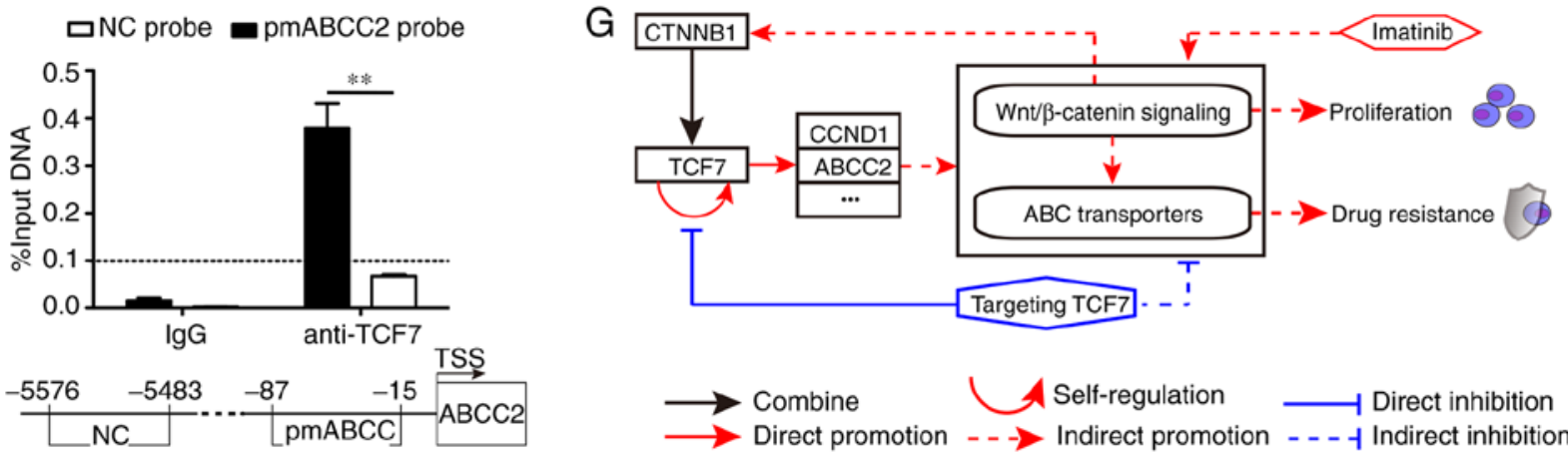

Figure 6. TCF7 knockdown neutralizes the intensity of $\mathrm{ABC}$ transporters and Wnt/ $\beta$-catenin signal in response to imatinib. (A) GSEA analysis shows the effects of TCF7 and imatinib on Wnt//3-catenin signaling pathways in CML imatinib-resistant cells. (B) Heatmap of the genes in TCF7_KD core enriched $\mathrm{ABC}$ transporters and $\mathrm{Wnt} / \beta$-catenin signaling pathways. (C) Western blot analysis showing the expression of ABCC2, CCND1, CTNNB1 and TCF7 proteins. (D) RT-qPCR analysis showing the expression of $A B C C 2$ and $C C N D 1$ mRNA in the Scramble and TCF7_KD groups. (E) Integrative genomics viewer (IGV) showing the recruitment of TCF7 to the $A B C C 2$ promoter region and the transcription level of $A B C C 2$ in K562/G01 cells with or without TCF7_KD treatment. (F) Recruitment of TCF7 in the $A B C C 2$ promoter region shown by ChIP-qPCR. (G) Role of TCF7 and imatinib on the Wnt and ABC transporters signaling pathway in imatinib-resistant CML. One-way ANOVA with Tukey's post hoc test were performed for F. Two-tailed Student's t-test was used for I. "P<0.05, ${ }^{* *} \mathrm{P}<0.01,{ }^{* * *} \mathrm{P}<0.001$. ns, not significant. GSEA, Gene Set Enrichment Analysis; TCF7, transcription factor 7; CML, chronic myeloid leukemia; KD, knockdown; CCND1, cyclin D1; CTNNB1, catenin $\beta 1$; ACTB, $\beta$-actin.

formation of imatinib-resistant cells is critical to overcoming CML recurrence. Further research should be performed at the level of single cells to achieve more detailed data of subsets of imatinib-resistant cells, and then exploration of the mechanism of protective feedback during cellular stress must be carried out. Moreover, our results could be further generalized if we conducted our investigations using primary tumor cells.

In summary, our study found that imatinib treatment induced protective upregulation of $\mathrm{Wnt} / \beta$-catenin and $\mathrm{ABC}$ transporter signals, and TCF7 knockdown neutralized this effect and restored imatinib sensitivity in imatinib-resistant cells. Additionally, this study showed that TCF7 konckdown could decrease the expression of CCND1 and ABCC2. Finally, our study revealed that regulation of the $\mathrm{Wnt} / \beta$-catenin/TCF7/ABC transporter signaling axis through TCF7 may become an effective strategy for overcoming imatinib resistance.

\section{Acknowledgements}

We thank Dr Jiwei Li for contributing to the RNA-seq analysis. 


\section{Funding}

This research study was supported by the National Natural Science Foundation of China (no. 81772255).

\section{Availability of data and materials}

The sequencing data was deposited in the GEO database with accession code GSE152220.

\section{Authors' contributions}

WF conceived and supervised the study. HZ performed the experiments and wrote the manuscript. YW and HY participated in analyses of the experimental results. $\mathrm{ZH}$ and $\mathrm{XW}$ made substantial contributions to the conception and design of the study. All authors read and approved this manuscript and agree to be accountable for all aspects of the research in ensuring that the accuracy or integrity of any part of the work are appropriately investigated and resolved.

\section{Ethics approval and consent to participate}

Not applicable.

\section{Patient consent for publication}

Not applicable.

\section{Competing interests}

The authors declare that they have no competing interests.

\section{References}

1. Rowley JD: Letter: A new consistent chromosomal abnormality in chronic myelogenous leukaemia identified by quinacrine fluorescence and Giemsa staining. Nature 243: 290-293, 1973.

2. Goldman JM and Melo JV: Targeting the BCR-ABL tyrosine kinase in chronic myeloid leukemia. N Engl J Med 344: 1084-1086, 2001.

3. Holyoake TL and Vetrie D: The chronic myeloid leukemia stem cell: Stemming the tide of persistence. Blood 129: 1595-1606, 2017.

4. Pasic I and Lipton JH: Current approach to the treatment of chronic myeloid leukaemia. Leukemia Res 55: 65-78, 2017.

5. Hehlmann R, Lauseker M, Sausele S, Pfirrmann M, Krause SW, Kolb HJ, Neubauer A, Hossfeld DK, Nerl C, Gratwohl A, et al: Assessment of imatinib as first-line treatment of chronic myeloid leukemia: 10-year survival results of the randomized CML study IV and impact of non-CML determinants. Leukemia 31: 2398-2406, 2017.

6. Redaelli S, Mologni L, Rostagno R, Piazza R, Magistroni V, Ceccon M, Viltadi M, Flynn D and Gambacorti-Passerini C: Three novel patient-derived BCR/ABL mutants show different sensitivity to second and third generation tyrosine kinase inhibitors. Am J Hematol 87: E125-E128, 2012.

7. Eide CA and Druker BJ: Understanding cancer from the stem cells up. Nat Med 23: 656-657, 2017.

8. Ashton JM, Balys M, Neering SJ, Hassane DC, Cowley G, Root DE, Miller PG, Ebert BL, McMurray HR, Land H and Jordan CT: Gene sets identified with oncogene cooperativity analysis regulate in vivo growth and survival of leukemia stem cells. Cell Stem Cell 11: 359-372, 2012.

9. Soverini S, Branford S, Nicolini FE, Talpaz M, Deininger MW, Martinelli G, Müller MC, Radich JP and Shah NP: Implications of BCR-ABL1 kinase domain-mediated resistance in chronic myeloid leukemia. Leuk Res 38: 10-20, 2014
10. Zhou H, Mak PY, Mu H, Mak DH, Zeng Z, Cortes J, Liu Q, Andreeff $M$ and Carter BZ: Combined inhibition of $\beta$-catenin and Bcr-Abl synergistically targets tyrosine kinase inhibitor-resistant blast crisis chronic myeloid leukemia blasts and progenitors in vitro and in vivo. Leukemia 31: 2065-2074, 2017.

11. Grassi S, Palumbo S, Mariottit V, Liberati D, Guerrini F, Ciabatti E, Salehzadeh S, Baratè C, Balducci S, Ricci F, et al: The WNT pathway is relevant for the BCR-ABL1-independent resistance in chronic myeloid leukemia. Front Oncol 9: 532, 2019.

12. Cheloni G, Tanturli M, Tusa I, Ho DeSouza N, Shan Y, Gozzini A, Mazurier F, Rovida E, Li S and Dello Sbarba P: Targeting chronic myeloid leukemia stem cells with the hypoxia-inducible factor inhibitor acriflavine. Blood 130: 655-665, 2017.

13. Rothe K, Lin H, Lin KB, Leung A, Wang HM, Malekesmaeili M, Brinkman RR, Forrest DL, Gorski SM and Jiang X: The core autophagy protein ATG4B is a potential biomarker and therapeutic target in CML stem/progenitor cells. Blood 123: 3622-3634, 2014

14. Jin Y, Zhou J, Xu F, Jin B, Cui L, Wang Y, Du X, Li J, Li P, Ren R and Pan J: Targeting methyltransferase PRMT5 eliminates leukemia stem cells in chronic myelogenous leukemia. J Clin Invest 126: 3961-3980, 2016.

15. Abraham A, Qiu S, Chacko BK, Li H, Paterson A, He J, Agarwal P, Shah M, Welner R, Darley-Usmar VM and Bhatia R: SIRT1 regulates metabolism and leukemogenic potential in CML stem cells. J Clin Invest 129: 2685-2701, 2019.

16. Chandran RK, Geetha N, Sakthivel KM, Aswathy CG, Gopinath P, Raj TV, Priya G, Nair J and Sreedharan H: Genomic amplification of BCR-ABL1 fusion gene and its impact on the disease progression mechanism in patients with chronic myelogenous leukemia. Gene 686: 85-91, 2019.

17. Chen JR, Jia XH, Wang H, Yi YJ and Li YJ: With no interaction, knockdown of Apollon and MDR1 reverse the multidrug resistance of human chronic myelogenous leukemia K562/ADM cells. Oncol Rep 37: 2735-2742, 2017.

18. He B, Bai Y, Kang W, Zhang X and Jiang X: LncRNA SNHG5 regulates imatinib resistance in chronic myeloid leukemia via acting as a CeRNA against MiR-205-5p. Am J Cancer Res 7: 1704-1713, 2017.

19. Mosimann C, Hausmann G and Basler K: Beta-catenin hits chromatin: Regulation of Wnt target gene activation. Nat Rev Mol Cell Biol 10: 276-286, 2009.

20. Vlad A, Röhrs S, Klein-Hitpass L and Müller O: The first five years of the Wnt targetome. Cell Signal 20: 795-802, 2008.

21. Yu SY, Li FY, Xing SJ, Zhao TY, Peng WQ and Xue HH: Hematopoietic and leukemic stem cells have distinct dependence on Tcf1 and Lef1 transcription factors. J Biol Chem 291: $11148-11160,2016$

22. Xu XL, Tang XD, Guo W, Yang K and Ren TT: TCF-1 participates in the occurrence of dedifferentiated chondrosarcoma. Tumor Biol 37: 14129-14140, 2016.

23. Yin H, Sheng Z, Zhang X, Du Y, Qin C, Liu H, Dun Y, Wang Q, Jin $\mathrm{C}$, Zhao $\mathrm{Y}$ and Xu T: Overexpression of SOX18 promotes prostate cancer progression via the regulation of TCF1, c-Myc, cyclin D1 and MMP-7. Oncol Rep 37: 1045-1051, 2017.

24. Chen WY, Liu SY, Chang YS, Yin JJ, Yeh HL, Mouhieddine TH, Hadadeh O, Abou-Kheir W and Liu YN: MicroRNA-34a regulates WNT/TCF7 signaling and inhibits bone metastasis in Ras-activated prostate cancer. Oncotarget 6: 441-457, 2015.

25. Shiokawa D, Sato A, Ohata H, Mutoh M, Sekine S, Kato M, Shibata T, Nakagama $\mathrm{H}$ and Okamoto K: The induction of selected Wnt target genes by Tcf1 mediates generation of tumorigenic colon stem cells. Cell Rep 19: 981-994, 2017.

26. Liu X, Liu X, Wu Y, Fang Z, Wu Q, Wu C, Hao Y, Yang X, Zhao J, Li J, et al: MicroRNA-34a attenuates metastasis and chemoresistance of bladder cancer cells by targeting the TCF1/LEF1 axis. Cell Physiol Biochem 48: 87-98, 2018.

27. Siu MK, Chen WY, Tsai HY, Chen HY, Yin JJ, Chen CL, Tsai YC and Liu YN: TCF7 is suppressed by the androgen receptor via microRNA-1-mediated downregulation and is involved in the development of resistance to androgen deprivation in prostate cancer. Prostate Cancer Prostatic Dis 20: 172-178, 2017.

28. Livak KJ and Schmittgen TD: Analysis of relative gene expression data using real-time quantitative PCR and the 2(-Delta Delta C(T)) method. Methods 25: 402-408, 2001.

29. Wang T, Huang Z, Huang N, Peng Y, Gao M, Wang X and Feng W: Inhibition of KPNB1 inhibits proliferation and promotes apoptosis of chronic myeloid leukemia cells through regulation of E2F1. Onco Targets Ther 12: 10455-10467, 2019. 
30. Subramanian A, Tamayo P, Mootha VK, Mukherjee S, Ebert BL Gillette MA, Paulovich A, Pomeroy SL, Golub TR, Lander ES and Mesirov JP: Gene set enrichment analysis: A knowledge-based approach for interpreting genome-wide expression profiles. Proc Natl Acad Sci USA 102: 15545-15550, 2005.

31. Shannon P, Markiel A, Ozier O, Baliga NS, Wang JT, Ramage D, Amin N, Schwikowski B and Ideker T: Cytoscape: A software environment for integrated models of biomolecular interaction networks. Genome Res 13: 2498-2504, 2003.

32. Yu G, Wang LG, Han Y and He QY: clusterProfiler: An R package for comparing biological themes among gene clusters. OMICS 16: 284-287, 2012.

33. Metsalu T and Vilo J: ClustVis: A web tool for visualizing clustering of multivariate data using Principal Component Analysis and heatmap. Nucleic Acids Res 43: W566-W570, 2015

34. Thorvaldsdóttir H, Robinson JT and Mesirov JP: Integrative Genomics Viewer (IGV): High-performance genomics data visualization and exploration. Brief Bioinform 14: 178-192, 2013.

35. Cramer-Morales K, Nieborowska-Skorska M, Scheibner K, Padget M, Irvine DA, Sliwinski T, Haas K, Lee J, Geng H, Roy D, et al: Personalized synthetic lethality induced by targeting RAD52 in leukemias identified by gene mutation and expression profile. Blood 122: 1293-1304, 2013.

36. Radich JP, Dai H, Mao M, Oehler V, Schelter J, Druker B, Sawyers C, Shah N, Stock W, Willman CL, et al: Gene expression changes associated with progression and response in chronic myeloid leukemia. Proc Natl Acad Sci USA 103: 2794-2799, 2006.

37. Giustacchini A, Thongjuea S, Barkas N, Woll PS, Povinelli BJ, Booth CAG, Sopp P, Norfo R, Rodriguez-Meira A, Ashley N, et al: Single-cell transcriptomics uncovers distinct molecular signatures of stem cells in chronic myeloid leukemia Nat Med 23: 692-702, 2017.

38. König J, Nies AT, Cui YH, Leier I and Keppler D: Conjugate export pumps of the multidrug resistance protein (MRP) family: Localization, substrate specificity, and MRP2-mediated drug resistance. Biochim Biophys Acta 1461: 377-394, 1999.

39. Lian G, Yuan J and Gao Y: In vitro transport ability of ABCC2 (G1249A) polymorphic variant towards anticancer drugs. Onco Targets Ther 13: 1413-1419, 2020.

40. Marchetti S, de Vries NA, Buckle T, Bolijn MJ, van Eijndhoven MA, Beijnen JH, Mazzanti R, van Tellingen O and Schellens JH: Effect of the ATP-binding cassette drug transporters $\mathrm{ABCB} 1, \mathrm{ABCG} 2$, and $\mathrm{ABCC} 2$ on erlotinib hydrochloride (Tarceva) disposition in in vitro and in vivo pharmacokinetic studies employing Bcrp1(-/-)/Mdrla/1b(-/-) (triple-knockout) and wild-type mice. Mol Cancer Ther 7: 2280-2287, 2008.

41. Kiyotani K, Mushiroda T, Imamura CK, Hosono N, Tsunoda T, Kubo M, Tanigawara Y, Flockhart DA, Desta Z, Skaar TC, et al: Significant effect of polymorphisms in CYP2D6 and ABCC2 on clinical outcomes of adjuvant tamoxifen therapy for breast cancer patients. J Clin Oncol 28: 1287-1293, 2010.
42. Yevshin I, Sharipov R, Kolmykov S, Kondrakhin Y and Kolpakov F: GTRD: A database on gene transcription regulation-2019 update. Nucleic Acids Res 47: D100-D105, 2019.

43. Ng LF, Kaur P, Bunnag N, Suresh J, Sung ICH, Tan QH, Gruber J and Tolwinski NS: WNT signaling in disease. Cells 8: 826, 2019.

44. Schuijers J, Mokry M, Hatzis P, Cuppen E and Clevers H: Wnt-induced transcriptional activation is exclusively mediated by TCF/LEF. EMBO J 33: 146-156, 2014.

45. Zhan Y, Feng J, Lu J, Xu L, Wang W and Fan S: Expression of LEF1 and TCF1 (TCF7) proteins associates with clinical progression of nasopharyngeal carcinoma. J Clin Pathol 72: 425-430, 2019.

46. Xu XG, Liu ZX, Tian F, Xu J and Chen YM: Clinical significance of transcription factor 7 (TCF7) as a prognostic factor in gastric cancer. Med Sci Monit 25: 3957-3963, 2019.

47. Kafka A, Bačić M, Tomas D, Žarković K, Bukovac A, Niirić N, Mrak G, Krsnik Ž and Pećina-Šlaus N: Different behaviour of DVL1, DVL2, DVL3 in astrocytoma malignancy grades and their association to TCF1 and LEF1 upregulation. J Cell Mol Med 23: 641-655, 2019.

48. Schneeweiss-Gleixner M, Byrgazov K, Stefanzl G, Berger D, Eisenwort G, Lucini CB, Herndlhofer S, Preuner S, Obrova K, Pusic P, et al: CDK4/CDK6 inhibition as a novel strategy to suppress the growth and survival of BCR-ABL1(T315I)+ clones in TKI-resistant CML. EBioMedicine 50: 111-121, 2019.

49. Eide CA, Zabriskie MS, Savage Stevens SL, Antelope O, Vellore NA, Than H, Schultz AR, Clair P, Bowler AD, Pomicter AD, et al: Combining the allosteric inhibitor asciminib with ponatinib suppresses emergence of and restores efficacy against highly resistant BCR-ABL1 mutants. Cancer Cell 36: 431-443.e5, 2019.

50. Au A, Baba AA, Azlan H, Norsa'adah B and Ankathil R: Clinical impact of $\mathrm{ABCC} 1$ and $\mathrm{ABCC} 2$ genotypes and haplotypes in mediating imatinib resistance among chronic myeloid leukaemia patients. J Clin Pharm Ther 39: 685-690, 2014

51. Trojani A, Pungolino E, Dal Molin A, Lodola M, Rossi G, D'Adda M, Perego A, Elena C, Turrini M, Borin L, et al: Nilotinib interferes with cell cycle, ABC transporters and JAK-STAT signaling pathway in $\mathrm{CD} 34^{+} /$lin $^{-}$cells of patients with chronic phase chronic myeloid leukemia after 12 months of treatment PLoS One 14: e0218444, 2019.

52. Mehrvar N, Abolghasemi H, Rezvany MR, Esmaeil Akbari M, Saberynejad J, Mehrvar A, Ehsani MA, Nourian M, Qaddoumi I and Movafagh A: Pattern of ABCC transporter gene expression in pediatric patients with relapsed acute lymphoblastic leukemia. Rep Biochem Mol Biol 8: 184-193, 2019.

This work is licensed under a Creative Commons Attribution-NonCommercial-NoDerivatives 4.0 International (CC BY-NC-ND 4.0) License. 